\title{
Novel multiplex real-time PCR assays reveal a high prevalence of diarrhoeagenic Escherichia coli pathotypes in healthy and diarrhoeal children in the south of Vietnam
}

Vu Thuy Duong ${ }^{1,2+}$, Le Thi Phuong Tu ${ }^{1+}$, Ha Thanh Tuyen ${ }^{1}$, Le Thi Quynh Nhi ${ }^{1,3}$, James I. Campbell', Pham Van Minh ${ }^{1}$, Hoang Le Phuc ${ }^{2}$, Tran Thi Hong Chau ${ }^{1}$, Nguyen Minh Ngoc ${ }^{4}$, Lu Lan Vi ${ }^{5}$, Claire Jenkins ${ }^{6}$, Iruka Okeke ${ }^{7}$, Ellen Higginson ${ }^{8}$ and Stephen Baker ${ }^{8^{*}}$ (i)

\begin{abstract}
Background: Diarrhoeagenic Escherichia coli (DEC) infections are common in children in low-middle income countries (LMICS). However, detecting the various DEC pathotypes is complex as they cannot be differentiated by classical microbiology. We developed four multiplex real-time PCR assays were to detect virulence markers of six DEC pathotypes; specificity was tested using DEC controls and other enteric pathogens. PCR amplicons from the six E. coli pathotypes were purified and amplified to be used to optimize PCR reactions and to calculate reproducibility. After validation, these assays were applied to clinical samples from healthy and diarrhoeal Vietnamese children and associated with clinical data.

Results: The multiplex real-time PCRs were found to be reproducible, and specific. At least one DEC variant was detected in 34.7\% (978/2815) of the faecal samples from diarrhoeal children; EAEC, EIEC and atypical EPEC were most frequent Notably, 41.2\% (205/498) of samples from non-diarrhoeal children was positive with a DEC pathotype. In this population, only EIEC, which was detected in 34.3\% (99/289) of diarrhoeal samples vs. 0.8\% (4/ 498) non-diarrhoeal samples $(p<0.001)$, was significantly associated with diarrhoea. Multiplex real-time PCR when applied to clinical samples is an efficient and high-throughput approach to DEC pathotypes.

Conclusions: This approach revealed high carriage rates of DEC pathotypes among Vietnamese children. We describe a novel diagnostic approach for DEC, which provides baseline data for future surveillance studies assessing DEC burden in LMICS.
\end{abstract}

Keywords: ETEC, EAEC, EIEC, EPEC, EHEC, Multiplex real-time PCR, Diarrhoea children, Healthy children, Co-infection

\footnotetext{
* Correspondence: sgb47@medschl.cam.ac.uk

${ }^{\dagger} \mathrm{Vu}$ Thuy Duong and Le Thi Phuong Tu contributed equally to this work.

${ }^{8}$ Cambridge Institute of Therapeutic Immunology \& Infectious Disease

(CITIID) Department of Medicine, Cambridge Biomedical Campus, University

of Cambridge, Cambridge CB2 OAW, UK

Full list of author information is available at the end of the article
}

\section{$\triangle B M C$}

(c) The Author(s). 2020 Open Access This article is licensed under a Creative Commons Attribution 4.0 International License, which permits use, sharing, adaptation, distribution and reproduction in any medium or format, as long as you give appropriate credit to the original author(s) and the source, provide a link to the Creative Commons licence, and indicate if changes were made. The images or other third party material in this article are included in the article's Creative Commons. licence, unless indicated otherwise in a credit line to the material. If material is not included in the article's Creative Commons licence and your intended use is not permitted by statutory regulation or exceeds the permitted use, you will need to obtain permission directly from the copyright holder. To view a copy of this licence, visit http://creativecommons.org/licenses/by/4.0/ The Creative Commons Public Domain Dedication waiver (http://creativecommons.org/publicdomain/zero/1.0/) applies to the data made available in this article, unless otherwise stated in a credit line to the data. 


\section{Background}

Diarrhoeal illness remains the second-highest cause of mortality and morbidity worldwide [1-3]; the main burden of this disease occurs in children in South Asia, Southeast Asia, and Africa [3]. Among the bacterial pathogens associated with diarrhoea in children, Escherichia coli are repeatedly the most common food borne pathogenic species identified [3-6]. However, identifying diarrhoea-causing $E$. coli can be complex, as pathogenic variants cannot be delineated from commensal $E$. coli solely by microbiological culture.

Diarrhoeagenic E. coli (DEC) can generally be divided into six pathotypes (enterotoxigenic E. coli, ETEC; enteroaggregative E. coli, EAEC; enteropathogenic E. coli, EPEC, enteroinvasive E. coli, EIEC; enterohemorrhagic E. coli, EHEC and shiga-toxin producing E. coli, STEC), based on specific virulence markers that are encoded on plasmids and/or chromosomal islands [7]. ETEC, EAEC, and EPEC have all been implicated in causing diarrhoea in young children in low-middle income countries (LMICs) [8-10].

For ETEC, heat-stable toxin producing strains (STETEC) are among the most important pathogens associated with diarrhoea in children [9-11]. Similarly, typical EPEC (possessing both eae and $b f p$ virulence genes) are more strongly associated with diarrhoea in children in developing regions than atypical EPEC strains which lack $b f p[6,12]$. EIEC are virtually indistinguishable from Shigella spp., which are essentially an independent genus within the broader $E$. coli population. STEC are commonly associated with food-borne disease outbreaks in developed countries and have higher mortality than other E. coli pathotypes due to sequelae of haemolytic uraemic syndrome (HUS) [13-15]. The epidemiology of STEC in LMICs, particularly in children in Southeast Asia, are not well described.

The proportion of diarrhoeal disease associated with DEC in Vietnam is not well investigated as measuring the prevalence of these pathogens in diarrhoeal cases and non-diarrhoeal controls is laborious and not routinely performed. Of the limited DEC studies conducted in Vietnam an investigation originating in Hanoi detected DEC in $22 \%$ of stool sample from diarrhoeal cases and $12 \%$ of controls using conventional multiplex PCR [16]. Here, we aimed to develop a set of standardized multiplex real-time PCR assays to identify the various DEC in complex samples in a comparatively short turnaround time. To establish the multiplex real-time PCR assays to identify the six DEC pathotypes we designed new or adapted existing specific primers and probes for nine DEC associated genes. The real-time PCR assays were optimized and then used to determine the prevalence of DEC in children with and without diarrhoea disease in Ho Chi Minh City (HCMC), Vietnam. Lastly, we combined these PCR data with available clinical data to identify clinical features in children infected with differing DEC pathotypes and to determine the potential effect of DEC in the stools of diseased and non-diseased children.

\section{Results \\ Multiplex real-time PCR assay for detecting diarrhoeagenic Escherichia coli}

We firstly validated PCR amplification for ETEC, EAEC, EIEC/Shigella, EPEC, and STEC in monoplex using cloned target sequences and then with genomic DNA extracted from the various $E$. coli pathovars. The sensitivity of the primer and probe sets was determined by generating a series of standard curves using 10-fold dilutions of control plasmid DNA. The limit of detection for all targets, including the uidA control, was five copies per reaction, with the exception of $a g g R$ which could be detected down to 50 copies per reaction. Each primer and probe set were tested against a panel of commonly isolated pathogens found in stool samples, which included Staphylococcus aureus, Klebsiella pneumoniae, Salmonella spp., Campylobacter coli, Campylobacter jejuni, Shigella sonnei, Shigella flexneri, Enterobacter, Proteus, norovirus, and rotavirus (these viruses were selected as they are most commonly found viruses in the stools of children with diarrhoea). No amplification was observed in any sample other than those containing $E$. coli.

Ultimately, the PCR assays were multiplexed into four reactions, and the sensitivity, intra-assay and inter-assay CVs across the nine target sequences were calculated for each multiplexed PCR reaction. The $\mathrm{Ct}$ values for each target were equivalent between the monoplex and multiplex reactions, confirming that multiplexing did not impact sensitivity. The intra-assay and inter-assay CVs ranged from 0.01 to $1.54 \%$ and from 0.01 to $2.12 \%$, respectively (Table 1). The linear regressions of the standard curves were between 0.992-0.999 for all targets tested. The resulting efficiency of the amplification ranged from 90.9 to $105.7 \%$, demonstrating the multiplex real-time PCR assays were well optimized, reproducible, and specific.

\section{The prevalence of diarrhoeagenic Escherichia coli from} faecal specimens of children hospitalized with diarrhoea Between May 2014 and April 2016, we amassed 2815 MC sweeps (i.e. faecal samples plated on MC media) from 3166 children hospitalized with bloody and/or mucoid diarrhoea at three tertiary hospitals in HCMC. A single faecal sample was collected from each child within their first 2 days of hospital admission for diarrhoea. The majority of patients were male $(1731 / 2815 ; 61.5 \%)$, 
Table 1 Reproducibility of the assays on diluted plasmid DNA containing cloned target sequences

\begin{tabular}{|c|c|c|c|c|c|c|c|c|c|}
\hline \multirow{2}{*}{$\begin{array}{l}\text { Target } \\
\text { sequence }\end{array}$} & \multirow{2}{*}{$\begin{array}{l}\text { Co-efficient of } \\
\text { variance (\%) }\end{array}$} & \multicolumn{8}{|c|}{ Target concentration } \\
\hline & & $5 \times 10^{7}$ & $5 \times 10^{6}$ & $5 \times 10^{5}$ & $5 \times 10^{4}$ & $5 \times 10^{3}$ & $5 \times 10^{2}$ & $5 \times 10^{1}$ & $5 \times 10^{0}$ \\
\hline \multirow[t]{2}{*}{ uidA } & Intra-assay variation ${ }^{a}$ & 0.13 & 0.09 & 0.14 & 0.26 & 0.34 & 0.12 & 0.82 & 0.52 \\
\hline & Inter-assay variation ${ }^{b}$ & 0.18 & 0.18 & 0.21 & 0.73 & 0.66 & 0.74 & 0.66 & 0.93 \\
\hline \multirow[t]{2}{*}{ eltB } & Intra-assay variation & 0.03 & 0.04 & 0.06 & 0.10 & 0.35 & 0.16 & 0.27 & 0.35 \\
\hline & Inter-assay variation & 0.07 & 0.11 & 0.05 & 0.23 & 0.41 & 0.50 & 0.38 & 0.67 \\
\hline \multirow[t]{2}{*}{ est $A$} & Intra-assay variation & 0.01 & 0.05 & 0.03 & 0.25 & 0.19 & 0.16 & 0.15 & 0.06 \\
\hline & Inter-assay variation & 0.15 & 0.03 & 0.04 & 0.05 & 0.52 & 0.36 & 0.12 & 0.76 \\
\hline \multirow[t]{2}{*}{$\operatorname{agg} R$} & Intra-assay variation & 0.11 & 0.08 & 0.08 & 0.15 & 0.20 & 0.37 & 0.29 & - \\
\hline & Inter-assay variation & 0.06 & 0.11 & 0.33 & 0.03 & 0.29 & 0.23 & 1.05 & - \\
\hline \multirow[t]{2}{*}{$\mathrm{ipaH}$} & Intra-assay variation & 0.19 & 0.17 & 0.20 & 0.12 & 0.12 & 0.60 & 0.15 & 0.11 \\
\hline & Inter-assay variation & 0.23 & 0.28 & 0.20 & 0.07 & 0.42 & 0.20 & 0.52 & 1.42 \\
\hline \multirow[t]{2}{*}{ eae } & Intra-assay variation & 0.07 & 0.24 & 0.29 & 0.06 & 0.26 & 0.76 & 0.20 & 0.48 \\
\hline & Inter-assay variation & 0.38 & 0.16 & 0.06 & 0.46 & 0.82 & 0.64 & 0.63 & 0.88 \\
\hline \multirow[t]{2}{*}{ bfpA } & Intra-assay variation & 0.03 & 0.09 & 0.11 & 0.17 & 0.50 & 0.90 & 0.63 & 0.90 \\
\hline & Inter-assay variation & 0.01 & 0.11 & 0.05 & 0.06 & 0.18 & 0.38 & 0.75 & 1.23 \\
\hline \multirow[t]{2}{*}{$r f b E$} & Intra-assay variation & 0.03 & 0.11 & 0.09 & 0.42 & 0.20 & 0.70 & 0.98 & 0.30 \\
\hline & Inter-assay variation & 0.02 & 0.04 & 0.10 & 0.23 & 0.60 & 1.49 & 1.29 & 1.08 \\
\hline \multirow[t]{2}{*}{ stx 1} & Intra-assay variation & 0.13 & 0.13 & 0.17 & 0.21 & 0.50 & 0.74 & 0.97 & 0.60 \\
\hline & Inter-assay variation & 0.22 & 0.50 & 0.71 & 0.98 & 1.19 & 1.57 & 1.95 & 0.55 \\
\hline \multirow[t]{2}{*}{$s t \times 2$} & Intra-assay variation & 0.11 & 0.14 & 0.18 & 0.17 & 0.25 & 1.54 & 0.81 & 0.24 \\
\hline & Inter-assay variation & 0.12 & 0.22 & 0.43 & 0.47 & 0.87 & 1.54 & 2.12 & 1.97 \\
\hline
\end{tabular}

${ }^{a}$ Intra-assay variation was calculated by measuring the co-efficient of variance of the $\mathrm{Ct}$ value on three concurrently run assays

${ }^{b}$ Inter-assay variation was calculated by comparing variation in $\mathrm{Ct}$ value on three independently run assays

with ages ranging from one month to 15 years (median age 10 months, IQR 6.6-17.1 months).

We employed the four multiplex real-time DEC PCRs on all 2815 MC sweeps to identify DEC targets potentially associated with clinical infection. At least one PCR amplification associated with a DEC variant was positive in $34.7 \%(978 / 2815)$ of the MC sweeps from paediatric patients hospitalized with diarrhoea. Among the DEC amplification positive samples, EAEC was the most common variant detected, with aggR amplified in 15.7\% (443/2815) of samples (Table 2). Other commonly amplified DEC targets included EIEC/Shigella and EPEC, which were identified in $12.4 \%(349 / 2815)$ and $12.2 \%$ (343/2815) of the MC sweep samples, respectively.

Within the EPEC pathotype, atypical EPEC positive samples (eae positive, $b f p A$ negative) were more prevalent than typical EPEC positive samples (eae positive, bfpA positive); $93.9 \%(322 / 343)$ vs. $6.1 \%$ (21/343), respectively. ETEC was detected in $6 \%(182 / 2815)$ of samples, with only a limited number of these samples $(8.2 \%$; 15/182) producing an amplicon for heat stable toxin (estA). Four diarrhoeal patients harboured samples containing the Shiga toxin-producing genes (stx1/stx2). Among the four cases associated with an STEC positive sample, one was positive for eae and one was positive
Table 2 DEC detected in children hospitalized with diarrhoea $(N=2815)$

\begin{tabular}{llll}
\hline Pathotypes & Target gene & $\mathrm{N}$ & $\%$ \\
\hline ETEC & & 182 & 6.5 \\
LT-ETEC & elt & 167 & 5.9 \\
ST-ETEC & est & 7 & 0.2 \\
LT-ST-ETEC & elt \& est & 8 & 0.3 \\
EAEC & aggR & 443 & 15.7 \\
EIEC/Shigella & ipaH & 349 & 12.4 \\
EPEC & & 343 & 12.2 \\
Atypical EPEC & eae & 322 & 11.4 \\
Typical EPEC & eae \& bfpA & 21 & 0.7 \\
EHEC/STEC & & 46 & 1.6 \\
O157 & eae \& rfbE_O157 & 20 & 0.7 \\
non-eae O157 & rfbE_O157 & 26 & 0.9 \\
& stxl/stx2 & 4 & 0.1 \\
Negative & & 1837 & 65.3 \\
\hline
\end{tabular}


for both eae and $r f b E \_O 157$. Of the two STEC cases that were amplification positive for eae and $r f b E_{-} O 157$, one was additionally positive for eltB (ETEC), the other was positive for $\operatorname{aggR}$ (EAEC).

\section{Clinical manifestations of diarrhoeagenic Escherichia coli mono-infection}

To investigate clinical syndromes associated with the various DEC in Vietnam, clinical data associated with the patients were accessed and compared between pathotype groups (Table S2). Patient samples from which multiple DEC pathogens were amplified were excluded. Notably, $\sim 70 \%$ of those with an ETEC, EAEC, EPEC, or STEC O157 positive sample were associated with mucoid, non-bloody diarrhoea, whereas EIEC/Shigella was significantly associated with visible bloody diarrhoea (39.7\%, 46/116, $p<0.001, x^{2}$ test). EAEC was the most commonly identified DEC in mono-infection. This pathotype was more commonly associated with children that had wasting or severe wasting $(13.5 \%, 23 /$ $170 ; p=0.013$, Fisher's exact test) than the other DEC variants. Whilst EHEC_O157 was identified less frequently than other pathotypes, it was significantly associated with moderate and severe dehydration $(40 \%, 8 / 20$; $p=0.010$, Fisher's exact test), which commonly required intravenous rehydration therapy.

Generally, we found that infections associated with DEC positive samples were uncomplicated; $>90 \%$ of patients had improved or recovered after 3 days and their median hospital stay was 5 days [IQR 3-7 days]. The use of antimicrobials within this study population was high, with $81.3 \%(1513 / 1861)$ of patients receiving empirical antimicrobial treatment prior to any diagnostic testing, which may impact on the detection of various DEC, depending on their susceptibility profile. Fluoroquinolones, specifically ciprofloxacin, were the most commonly used class of antimicrobials in those with a DEC in their stool (957/1512, 63.3\%).

\section{Diarrhoeagenic Escherichia coli from faecal specimens of diarrhoeal hospitalized children vs. healthy non- diarrhoeal children}

Between March 2016 and August 2016, 498 MC sweeps were additionally collected from faecal samples taken from healthy children residing in HCMC and participating in a cohort study [17]. The majority of healthy children were male $(269 / 498 ; 54.0 \%)$, with their age when sampled ranging from 24 months to 5 years (median age 46.4 months, IQR 35.6-52.5 months). In a comparable manner to the diarrhoeal samples, we screened the MC extractions from these healthy children with the multiplex real-time PCRs to detect DEC. At least one pathotype of DEC was detected in 41.2\% (205/498) of samples associated with non-diarrhoeal children (Table 3).

To determine the prevalence and distribution of the various DEC in healthy and diarrhoeal children, we compared the data from the healthy children with a subset of the data from matched children in the diarrhoeal study which were between the ages of 2 and 5 years old (319 children; median age 31.5 months, IQR 26.7-38.9 months). The prevalence of ETEC, EAEC, and EHEC_ O157 in faecal samples was not significantly different between children with or without diarrhoea (Table 3, Fig. 2). Furthermore, EPEC was detected significantly

Table 3 Direct comparison of DEC detected in samples from children hospitalized with diarrhoea and healthy children

\begin{tabular}{|c|c|c|c|c|c|c|}
\hline \multirow{2}{*}{$\begin{array}{l}\text { Diarrhoeagenic } \boldsymbol{E} \text {. coli } \\
\text { Number }\end{array}$} & \multirow[t]{2}{*}{ Target gene } & \multicolumn{2}{|c|}{ Diarrhoea N (\%) } & \multicolumn{2}{|c|}{ Non-diarrhoea N (\%) } & \multirow[t]{2}{*}{$\boldsymbol{p}$ value $^{*}$} \\
\hline & & \multicolumn{2}{|l|}{319} & \multicolumn{2}{|l|}{498} & \\
\hline ETEC & & 29 & (9.1) & 42 & (8.4) & 0.745 \\
\hline LT-ETEC & elt & 25 & (7.8) & 39 & (7.8) & 0.998 \\
\hline ST-ETEC & est & 1 & $(0.3)$ & 3 & (0.6) & 1.000 \\
\hline LT-ST-ETEC & elt \& est & 3 & $(0.9)$ & 0 & $(0.0)$ & 0.059 \\
\hline EAEC & $\operatorname{aggR}$ & 50 & $(15.7)$ & 89 & $(17.9)$ & 0.415 \\
\hline EIEC/Shigella & $\mathrm{ipaH}$ & 93 & $(29.2)$ & 4 & $(0.8)$ & $<0.001$ \\
\hline EPEC & & 39 & $(12.2)$ & 93 & (18.7) & 0.015 \\
\hline Atypical EPEC & eae & 38 & (11.9) & 90 & $(18.1)$ & 0.018 \\
\hline Typical EPEC & eae \& bfpA & 1 & $(0.3)$ & 3 & (0.6) & 1.000 \\
\hline EHEC/STEC & & 13 & $(4.1)$ & 20 & $(4.0)$ & 0.712 \\
\hline 0157 & eae \& rfbE_O157 & 5 & (1.6) & 5 & $(0.6)$ & 0.524 \\
\hline \multirow[t]{2}{*}{ non-eae 0157} & rfbE_O157 & 8 & $(2.5)$ & 18 & (3.4) & 0.379 \\
\hline & stx $1 / s t \times 2$ & 0 & - & 7 & (1.4) & 0.033 \\
\hline Negative & & 163 & $(51.1)$ & 293 & (58.8) & 0.030 \\
\hline
\end{tabular}

${ }^{*} p$ value from $x^{2}$ test or Fisher's exact test 
more frequently in the non-diarrhoeal samples (18.7\%, 93/498) than the diarrhoeal samples $(11.4 \%, 33 / 289)$ $\left(p=0.019, \chi^{2}\right.$ test) (Table 3$)$. The only DEC that was significantly associated with the diarrhoeal samples was EIEC/Shigella, which was detected in 34.3\% (99/289) of diarrhoeal samples vs. $0.8 \%(4 / 498)$ non-diarrhoeal samples $(p<0.001$, Fisher's exact test).

The distribution of DEC co-infection among the cases and the controls was complex and highly variable (Fig. 2). The most common co-infections in the diarrhoeal group were EAEC + EIEC/Shigella $(3.8 \%, 12 / 319)$ and EAEC + EIEC/Shigella + ETEC (2.2\%, 7/319); whereas EPEC + EAEC $(3.4 \%, 17 / 498)$ was more common in the healthy control group. Co-infection with more than one DEC was more likely to be associated with diarrhoeal disease than with healthy controls $(16.3 \%, 52 / 319$ vs. $9.6 \%, 48 / 498, p=$ $0.005, X^{2}$ test). However, due to the predominant presence of EIEC/Shigella in the diarrhoeal group, EIEC/Shigella infection was a potential confounder.

To disaggregate the potential confounding effect of EIEC/Shigella, we performed binary univariate and multivariate logistic regression to identify variables and DEC that were associated with diarrhoeal disease in children aged 24-60 months (Table 4). In the univariate model, co-infection with ETEC, mono-infection with EIEC/Shigella, co-infection with EIEC/Shigella, and coinfection without EPEC, EHEC_O157, and STEC were significantly associated with diarrhoea. However, after controlling for confounders, only mono or co-infection with EIEC/Shigella and wasting were determined to be

Table 4 Univariate and multivariate analysis of DEC mono-infection and co-infection associated with diarrhoeal disease among children from 24 to 60 months of age using binary logistic regression model

\begin{tabular}{|c|c|c|c|c|c|c|}
\hline \multirow[t]{2}{*}{ Variable } & \multicolumn{3}{|c|}{ Univariate Model } & \multicolumn{3}{|c|}{ Multivariate Model } \\
\hline & Odds Ratio & 95\% Confidence Interval & $\boldsymbol{P}$-value ${ }^{c}$ & Odds Ratio & 95\% Confidence Interval & $\boldsymbol{P}$-value ${ }^{\mathrm{d}}$ \\
\hline \multicolumn{7}{|l|}{ Types of infection ${ }^{a}$} \\
\hline Mono-infection with ETEC & 0.39 & $0.15-1.05$ & 0.062 & 0.32 & $0.11-0.94$ & 0.037 \\
\hline Co-infection with ETEC & 2.27 & $1.21-4.27$ & 0.011 & & & \\
\hline Co-infection without ETEC & 1.74 & $1.00-3.02$ & 0.051 & & & \\
\hline Mono-infection with EAEC & 0.51 & $0.28-0.93$ & 0.028 & 0.45 & $0.24-0.86$ & 0.015 \\
\hline Co-infection with EAEC & 1.75 & $1.06-2.89$ & 0.030 & & & \\
\hline Co-infection without EAEC & 2.55 & $1.19-5.46$ & 0.016 & & & \\
\hline Mono-infection with EIEC & 52.13 & $12.57-216.21$ & $<0.001$ & 49.66 & $11.90-207.24$ & $<0.001$ \\
\hline Co-infection with EIEC & 31.46 & $7.47-132.47$ & $<0.001$ & 35.60 & $8.28-153.12$ & $<0.001$ \\
\hline Co-infection without EIEC & 0.66 & $0.37-1.20$ & 0.173 & 0.63 & $0.34-1.18$ & 0.149 \\
\hline Mono-infection with EPEC & 0.55 & $0.32-0.95$ & 0.031 & 0.59 & $0.34-1.02$ & 0.057 \\
\hline Co-infection with EPEC & 1.22 & $0.66-2.25$ & 0.525 & & & \\
\hline Co-infection without EPEC & 2.97 & $1.65-5.34$ & $<0.001$ & & & \\
\hline Mono-infection with EHEC & 0.90 & $0.33-2.44$ & 0.834 & 0.96 & $0.35-2.64$ & 0.937 \\
\hline Co-infection with EHEC & 1.14 & $0.44-3.01$ & 0.785 & & & \\
\hline Co-infection without EHEC & 2.19 & $1.36-3.52$ & 0.001 & & & \\
\hline Mono-infection with STEC & - & & & & & \\
\hline Co-infection with STEC & - & & & & & \\
\hline Co-infection without STEC & 2.17 & $1.39-3.40$ & 0.001 & & & \\
\hline \multicolumn{7}{|l|}{ Gender } \\
\hline Female & 0.81 & $0.61-1.07$ & 0.142 & 0.65 & $0.47-0.91$ & 0.013 \\
\hline \multicolumn{7}{|l|}{ Growth ${ }^{\text {b }}$} \\
\hline Obese & 0.57 & $0.35-0.92$ & 0.022 & 0.51 & $0.29-0.89$ & 0.019 \\
\hline Overweight & 0.88 & $0.57-1.36$ & 0.560 & 1.00 & $0.62-1.62$ & 0.998 \\
\hline Risk of overweight & 0.68 & $0.46-1.01$ & 0.053 & 0.83 & $0.54-1.27$ & 0.390 \\
\hline Wasted & 19.13 & $2.48-147.54$ & 0.005 & 19.58 & $2.43-157.92$ & 0.005 \\
\hline
\end{tabular}

${ }^{a}$ Odds Ratio with the reference was non-infection status

b Odds Ratio with the reference was normal growth status

c $P$-value considered significant when $\mathrm{p}<0.01$

${ }^{d} P$-value considered significant when $p<0.05$ 
significantly associated with diarrhoea. Conversely, mono-infection with ETEC, EAEC, and obesity were significantly more common in the non-diarrhoeal children.

\section{Discussion}

Here, we developed and applied an efficient and robust collection of real-time PCR assays for identifying DEC in MC sweeps isolated from stool samples from a collection of healthy and diarrhoeal children. This approach, in comparison to the traditional method, is straightforward, cost-effective and has a comparatively short turn-around time [18]. Ultimately, the four multiplex real-time PCR assays could detect ten target sequences corresponding with six pathotypes of DEC, which permitted detection of these pathogens with a high degree of accuracy and utility. However, there are some limitations with our approach. Due to their high genetic similarity, we are unable to differentiate between EIEC and Shigella spp. by using real-time PCR, as the invasion plasmid antigen $\mathrm{H}(\mathrm{ipaH})$ and the uidA (the internal control gene for E. coli) are present in both [19]. Further limitations of this approach are associated with issues of how pathotypes such as EPEC, EHEC, and STEC are defined. Through bacterial genomics, we know that organisms lacking either eae or stx or both may still belong to the EHEC group [20, 21]. In addition, the stx genes have been found in other pathotypes of E. coli [22, 23]. Therefore, it is impossible to definitively assign an $E$. coli to a DEC pathotype without genome sequencing. However, pathotyping DEC through detecting virulence genes remains useful for assessing the potential prevalence of the various pathogenic forms of $E$. coli in any given population. In addition to the methodological constraints of the study, as our control samples came from healthy children over 12 months of age, we could not evaluate associations with diarrhoea in children under 1 year of age and we recognise that co-infection with organisms that were not detected may impact on disease presentation.

While ETEC is the most common DEC internationally, the prevalence of ETEC in this setting was found to be considerably lower than other regions $[9,18]$. This result is probably due to the study inclusion criteria, as only children presenting with bloody and/or mucoid diarrhoeal illness were enrolled, whereas ETEC is most commonly associated with watery diarrhoea [7]. Here, LT-ETEC were more prevalent than ST-ETEC, which is consistent with earlier studies on ETEC infections in children. However, in these previous studies the association between LT-ETEC infection and diarrhoea was weak $[6,9,18]$. In contrast, in the Global Enteric Multicentre Study (GEMS), ST-ETEC but not LT-ETEC was attributed as a major cause of diarrhoea in all age groups [24]. To determine whether ST-ETEC is an important pathogen in Vietnam, it will be necessary to carry out additional studies focusing on children presenting with watery diarrhoea.

EAEC was the most commonly detected pathotype in children with diarrhoea in this study, which is again consistent with earlier studies that reported high detection rates of EAEC compared to other DEC in Vietnam [16, 25]. Several articles have raised the possibility that not all EAEC are pathogenic, and that variants within this group may have different propensities to cause disease [26-31]. However, several outbreaks and human volunteer studies have unequivocally shown that some EAEC can cause disease [26-31]. Here, one third of EAEC mono-infections required antimicrobial IV treatment (i.e. the third generation cephalosporins or imipenem; data not shown) associated with a more severe disease presentation. Notably, samples from three children in this study generated positive PCR amplicons for both EAEC and stx. These cases may represent mixed infections of EAEC and STEC, or potentially hybrid organisms, such as those associated with an extensive outbreak in Europe in 2011 [23]. Although EAEC was not associated with diarrhoea in children within the 2460-month age group in this study, it was the most commonly detected pathotype from children with wasting. This observation is consistent with the findings of the recent the MAL-ED study, which reported that EAEC infection is associated with growth shortfall, irrespective of disease [32].

EPEC was the most common DEC gene target amplified from faecal samples of diarrhoea and non-diarrhoea children. The overwhelming majority of the amplicons generated from both healthy and diseased cohorts were associated with aEPEC. These data are again consistent with EPEC literature, which suggests that typical EPEC is commonly identified in the African continent $[18,33]$, while atypical EPEC tends to predominate in other regions [34]. A case-control study conducted in seven LMICs found that typical EPEC infections were significantly associated with mortality in children under 5 years [6]. The high prevalence of atypical EPEC positive samples in our study group (24-60 months of age) may be partially associated with colonization in the first year of life, as asymptomatic infection with ETEC, EAEC, and EPEC have previously been associated with weaning and the termination of breastfeeding [35].

STEC O157 cause severe diarrhoea and are associated with a high mortality rate in food-borne outbreaks in western countries [36]. EHEC_O157 in this setting had a low prevalence and more than half the positive samples were positive for the $r f b E \_O 157$ gene alone, which suggests these are likely to be of lower pathogenicity. Only two samples that tested positive for EHEC_O157 also produced amplicons for the Shiga-toxin gene (stx2), 
suggesting that O157-STEC is not a significant cause of gastrointestinal symptoms in this location. In the age matched comparison, STEC were isolated from children in the healthy group only. This observation is consistent with data originating in Indonesia, where STEC was detected significantly more frequently in non-diarrhoeal children [37].

In previous studies, co-infection with more than one DEC (or with other enteric pathogens) was found to be significantly associated with diarrhoea [26, 38-41]. In this study, we found that co-infection with DEC was not associated with diarrhoea and was also common in healthy children. Notably, only co-infection with EIEC/ Shigella was significantly associated with diarrhoeal disease. However, as EIEC/Shigella infection alone was highly significantly associated with diarrhoeal illness, the contribution of other DEC to disease in EIEC/Shigella infection is unclear. In a multivariate logistic regression model, DEC co-infection in the absence of EIEC/Shigella was not associated with diarrhoea. This suggests that EIEC/Shigella is the most important cause of DEC mediated moderate-to-severe diarrhoea in this setting.

\section{Conclusions}

Multiplex real-time PCR is an efficient method for detecting the six major pathotypes of DEC in a collection of clinical samples. This new methodology provides a useful alternative to classical microbiology for large-scale microbiological and epidemiological studies. Using this approach, we found a high prevalence of DEC in the stools of both healthy and diarrhoeal children in Vietnam. EAEC and atypical EPEC were the most commonly detected DEC in both groups; whereas, EIEC/Shigella was the only DEC significantly associated with diarrhoeal disease. This study provides new methodology and baseline data for further clinical, epidemiological, and genomic studies in Vietnam and across Southeast Asia and shows that DEC are highly prevalent but not generally associated with diarrhoeal disease in Vietnam.

\section{Methods}

\section{Study design}

Children aged $\leq 15$ years with diarrhoeal illness admitted to one of the three collaborating tertiary hospitals in HCMC, Vietnam from May 2014 to April 2016 were eligible for enrolment. Those with diarrhoeal illness (cases) were defined as $\geq 3$ passages of loose stools within 24-h period along with at least one loose stool containing blood and/or mucus [42]. We excluded children if they had suspected or confirmed intussusception at the time of enrolment [43]. Controls were healthy children between the age of 12-60 months enrolled in diarrhoeal disease cohort in District 8 in HCMC from 2014 to 2016 [17]. The enrolled children attended $\mathrm{HVH}$ for routine health check every six months. An anal swab of healthy child was collected by study nurses at these routine visits.

\section{Primer and probe design}

The selected target genes for each pathotype were: ETEC, eltB (heat-labile toxin) and/or estA (heat-stable toxin); EAEC, aggR (transport regulator gene [44]); EIEC, $i p a H$ (secreted protein encoded on pINV [19]); EPEC, eae (encoding the intimin adherence gene [7]) and $b f p A$ (encoding a structural component of the bundle forming pilus [45]); STEC, stx 1 and/or stx2 (Shiga toxins [7]); and $r f b E \_O 157$ (encoding the lipopolysaccharide O157 antigen, the most common STEC serogroup in regions where surveillance data is available). The uidA gene, which encodes beta-glucuronidase and is present in all E. coli, was used as an internal control to monitor both DNA extraction and PCR amplification. A flowchart of the combined assay strategy is shown in Fig. 1.

We classified the DEC amplification results using the following approach; ETEC positive samples were divided into LT-ETEC (eltB positive only); ST-ETEC (estA positive only); and LT-ST-ETEC (eltB and estA positive). Amplification of $\operatorname{aggR}$ was sufficient for classification as EAEC and a positive amplification for ipaH identified EIEC/Shigella. EPEC positive samples were divided into typical EPEC (carrying both eae and $b f p A$ ) and atypical EPEC (the presence of eae only). The STEC pathotype was identified by the presence of stx 1 and/or stx2, and the presence or absence of $r f b \_O 157$ was used to differentiate between STEC O157 and the non-O157 STEC serogroups. STEC that have the potential to cause HUS carry additional virulence genes, specifically eae and $\operatorname{aggR}$.

The primer and probe sequences for aggR, ipaH, eae, and uidA) were adapted from previous studies [46-49]. Reference sequences were downloaded from GenBank eltB, estA (STh), bfpA, rfbE_O157, stx1 and stx2 (Table S1) and aligned using AlignX (Vector NTI, Invitrogen) to identify conserved regions within the gene sequence. Primer Quest (IDT, USA) was employed to generate primers and probes of amplicon size 100 to $150 \mathrm{bp}$. To find optimal pairs, candidate primers and probes were analysed for Tm, \%GC, hairpin, self-dimer and heterodimer using Oligo Analyzer 3.1 (http://sg.idtdna.com/ calc/analyzer). Final primer/probe candidates were blasted against PrimerBLAST (https://www.ncbi.nlm.nih. gov/tools/primer-blast/) to confirm the in-silico specificity of the selected sequences. The selected primer and probe sequences are shown in Table 5 .

\section{Isolation of nucleic acids and construction of control plasmids}

Nucleic acids were purified from prototypic E. coli strains and a variety of other gastrointestinal pathogens 


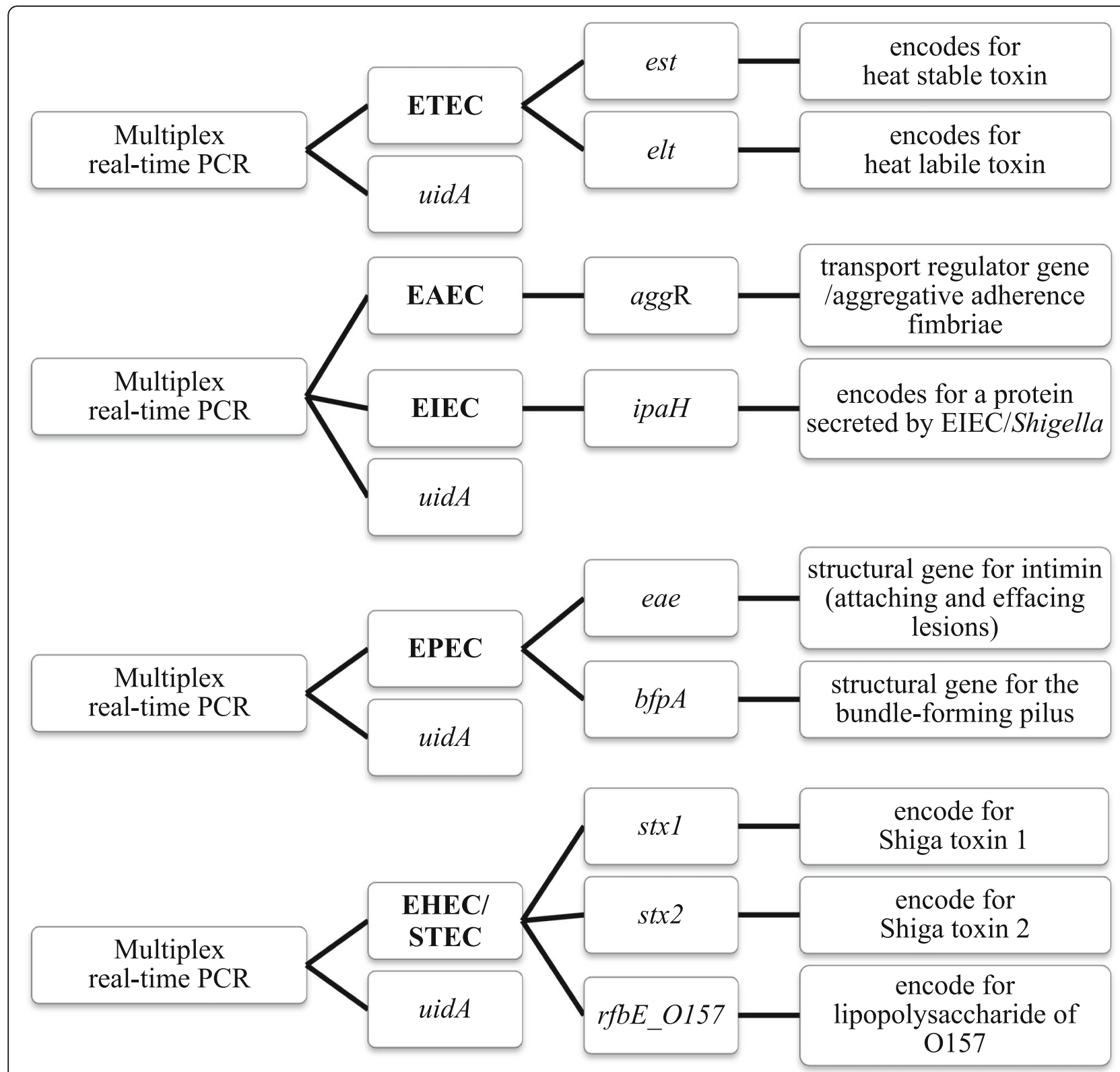

Fig. 1 Multiplex PCR strategy. Flowchart showing the four multiplex real-time PCR assays for detecting target sequences of DEC; uidA (gene encoded for $\beta$-glucuronidase and presented in all E. coli) was selected as an internal control

using Wizard Genomic DNA Purification Kit (Promega). PCR amplicons were generated for each of the 11 target genes and ligated into $\mathrm{pCR}^{\mathrm{m}}$ 2.1$\mathrm{TOPO}^{\circ}$ (Invitrogen, Applied Biosystem, UK). Purified plasmids were used as template to optimize PCR reactions and measure assay reproducibility. Plasmid concentrations $(\mathrm{ng} / \mu \mathrm{l})$ were quantified using a Nanodrop spectrophotometer (Thermo-Scientific, UK), and converted to copy number using the URI Genomics and Sequencing Center online tool (http:// cels.uri.edu/gsc/cndna.html).

\section{Real-time PCR}

Multiplex real-time PCR reactions were performed in a $25 \mu \mathrm{l}$ reaction mixture containing a final concentration of $1 \mathrm{X}$ buffer, $0.2 \mathrm{mM}$ deoxynucleoside triphosphates (dNTPs), $3.5 \mathrm{mM}$ of $\mathrm{MgCl}_{2}, 0.2 \mu \mathrm{M}$ of each forward and reverse primers, $0.08 \mu \mathrm{M}$ of each probe and $1 \mathrm{U}$ of Hotstart Taq polymerase (QIAGEN, Germany). Five $\mu \mathrm{l}$ of DNA template was used for each PCR reaction. The real-time PCR cycling conditions were as follows: $95^{\circ} \mathrm{C}$ for $15 \mathrm{~min}$, followed by 45 cycles of $95^{\circ} \mathrm{C}$ for $15 \mathrm{~s}$, then $60^{\circ} \mathrm{C}$ for 60s, using the Light Cycler 480 II system 
Table 5 Sequences of primers and probes to detect DEC in this study

\begin{tabular}{|c|c|c|c|}
\hline Diarrhoeagenic $\boldsymbol{E}$. coli target & Primer/probe name & Sequence $*\left(5^{\prime}-3^{\prime}\right)$ & Amplicon size (bp) \\
\hline \multirow[t]{6}{*}{ ETEC } & elt_ETEC_F & CTCGGTCAGATATGYGATTCTT & 100 \\
\hline & elt_ETEC_R & AACATTTCAGGTCGAAGTCC & \\
\hline & elt_ETEC_probe & FAM-TGTGTCCTTCATCCTTTC AATGGCTT-BHQ1 & \\
\hline & est_ETEC_F & GCTAAACCAGYAGRGTCTTCAA & 137 \\
\hline & est_ETEC_R & GCAGGATTACAACACAATTCAC & \\
\hline & est_ETEC_probe & LCCyan500-AGTRGTCCTGAAA GCATGAATAGTAGCA-BHQ1 & \\
\hline \multirow[t]{3}{*}{ EAEC } & $a g g R \_F$ & CCATTTATCGCAATCAGATTAA & $92[46]$ \\
\hline & aggR_R & CAAGCATCTACTITTGATATTCC & \\
\hline & aggR_probe & FAM-CAGCGATACATTAAGA CGCCTAAAGGA-BHQ1 & \\
\hline \multirow[t]{3}{*}{ EIEC/Shigella } & ipaH_F & AGGTCGCTGCATGGCTGGAA & 99 [47] \\
\hline & ipaH_R & CACGGTCCTCACAGCTCTCA & \\
\hline & ipaH_probe & LCCyan500-AACTCAGTGCCTCT GCGGAGCTTCGACA-BHQ1 & \\
\hline \multirow[t]{3}{*}{ EPEC/EHEC } & eae_F & CATTGATCAGGATTITCTGGTGA TA & $102[48]$ \\
\hline & eae_R & CTCATGCGGAAATAGCCGTTA & \\
\hline & eae_probe & FAM-ATAGTCTCGCCAGTA TTCGCCACCAATACC-BHQ1 & \\
\hline \multirow[t]{3}{*}{ EPEC } & $b f p A_{-} E P E C_{-}$ & GTCTRTCTITGATTGAATCKGC & 108 \\
\hline & $b f p A \_E P E C \_R$ & CATTCTGYGMCTTATTGGAATC & \\
\hline & bfpA_EPEC_probe & LCCyan500-ACCGTTACYGCM GGTGTGATGTTT-BHQ1 & \\
\hline \multirow[t]{6}{*}{ STEC } & stx1_EHEC_F & GCATCTGATGAGTTTCCTTCTA & 113 \\
\hline & $s t \times 1 \_E H E C \_R$ & GTTCTGCGCATCAGAATTG & \\
\hline & stx1_EHEC_probe & FAM-AAGAGKCCGTGGGA TTACGCACAAT-BHQ1 & \\
\hline & $s t \times 2 \_E H E C \_F$ & ACRACGGACAGCAGYTATWC & 111 \\
\hline & $s t \times 2 \_E H E C \_R$ & GAACTCCATTAAMKCCAGATA & \\
\hline & stx2_EHEC_probe & LC Red 610-ATGCAAATCAGTCGTCA CTCACTGGT-BHQ1 & \\
\hline \multirow[t]{3}{*}{ EHE CO157 } & rfbE_O157_F & CAAGTCCACAAGGAAAGTAAAG & 111 \\
\hline & rfbE_O157_R & GAGTITATCTGCAAGGTGATTC & \\
\hline & rfbE_O157_probe & LCCyan500-AACTCAGTGCCTCT GCGGAGCTTCGACA-BHQ1 & \\
\hline \multirow[t]{3}{*}{ Internal control } & uidA_F & GTGTGATATCTACCCGCTTCGC & $82[49]$ \\
\hline & uidA_R & AGAACGGTTTGTGGTTAATCAGGA & \\
\hline & uidA_probe & CY5-TCGGCATCCGGTCAGTGGCAGT-BHQ2 & \\
\hline
\end{tabular}

${ }^{*} \mathrm{R}(\mathrm{A} / \mathrm{G}), \mathrm{Y}(\mathrm{C} / \mathrm{T}), \mathrm{S}(\mathrm{G} / \mathrm{C}), \mathrm{W}(\mathrm{A} / \mathrm{T}), \mathrm{M}(\mathrm{A} / \mathrm{C}), \mathrm{K}(\mathrm{G} / \mathrm{T})$ according to International Union of Pure and Applied Chemistry (IUPAC)

Probe detection format (Roche Light Cycler II 480) as followed FAM: 498-580; LCCyan500: 440-488; CY5: 618-660; LC Red 610: 533-610; BlackBerry ${ }^{\circledR}$ Quencher: BHQ1, BHQ2

(Roche, Germany). The threshold cycle $(\mathrm{Ct})$ value for a positive result was considered to be 38 or less.

\section{Reproducibility and linearity analysis}

The precision and reproducibility of the real-time PCR assays were assessed using the co-efficient of variance (CV\%), measured by dividing the standard deviations of the $\mathrm{Ct}$ values by the mean $\mathrm{Ct}$ values for each selected concentration. The $\mathrm{Ct}$ values of three replicates assayed simultaneously were compared to measure intra-assay reproducibility. The inter-assay reproducibility was calculated from data generated on three separate days. Linearity was determined by linear regression, using $\mathrm{Ct}$ values produced from 10-fold dilutions of control plasmid DNA.

\section{Specimen culture and storage}

Diarrhoeal faecal specimens were collected in sterile containers and transported to the laboratory within $24 \mathrm{~h}$ [43]. Anal swabs from non-diarrhoeal children were also transported to the laboratory within $24 \mathrm{~h}$ for processing. Specimens were inoculated onto MacConkey agar (MC, Oxoid), and incubated at $37^{\circ} \mathrm{C}$ for $18-24 \mathrm{~h}$ [43]. Following incubation, a sweep of colonies was taken from the entire MC agar plate and suspended in $20 \%$ glycerol in 


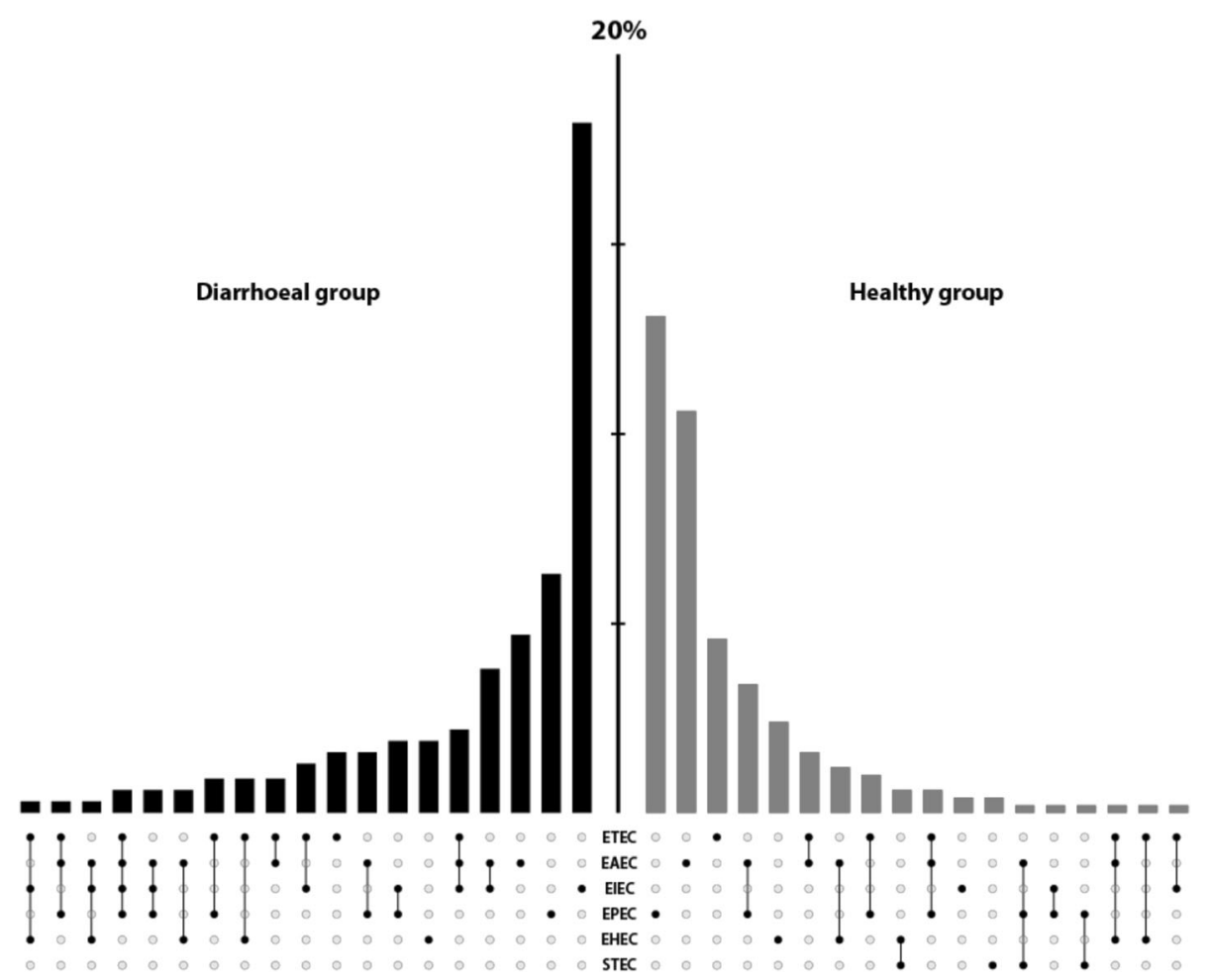

Fig. 2 Mono- and co-infection with DEC in the 24-60-month-old healthy and diarrhoeal and healthy children. Bar chart demonstrating the proportion of cases and controls with each combination of DEC pathotypes, with the most frequently isolated DEC pairings located near the centre, the scale (y axis) in 5\% increments. The dots and lines between dots at the base of the chart show the co-infection status for six pathotypes of DEC. DEC co-infection patterns among diarrhoea group ( $N=319$; black) and healthy group ( $N=498$; grey)

Brain Heart Infusion (BHI) broth, before being stored at $-80^{\circ} \mathrm{C}$.

\section{Crude DNA extraction}

Eighty $\mu \mathrm{l}$ of the stored colony sweep suspension was centrifuged at $4000 \mathrm{rpm}$ for $10 \mathrm{~min}$, and the pellet was resuspended in $80 \mu \mathrm{l}$ of molecular grade water (Sigma). The resulting suspension was mixed by gently pipetting up and down, before being boiled at $96^{\circ} \mathrm{C}$ for $10 \mathrm{~min}$ and cooled to room temperature. The lysate was centrifuged at $4000 \mathrm{rpm}$ for $10 \mathrm{~min}$ to remove cellular debris, and $5 \mu \mathrm{l}$ of supernatant was subjected to the real-time PCR assays.

\section{Data collection and statistical analysis}

Data were exported into Microsoft Excel (Microsoft, USA), and analysed using Stata v11 (StataCorp, College Station TX, USA). Descriptive comparisons between groups were conducted using non-parametric tests including $X^{2}$ test or Fisher's exact test for categorical variables and the Kruskal-Wallis test for continuous data. Growth status of participating patients were assessed using the WHO global database on growth and nutrition and Prevention and Management of Obesity for
Children and Adolescents-Healthcare guidelines using the macro package of Stata v11 developed by WHO [50, 51]. Due to the age difference between diarrhoeal and non-diarrhoeal groups, the comparative analyses were performed between all the children in healthy group and the subset children in the diarrhoea group that were aged 24-60 months. Logistic regression was performed to determine the associations with diarrhoea using each type of infection considered as an independent variable. Infections were classified as mono-infection of each pathotype of DEC or co-infections of each specific pathotype and other pathotypes. The types of co-infection were repeated due to multi pathotype co-infection; hence the $p$-value for univariate model was considered significant when $p<0.01$. Multivariable logistic regression models were performed and incorporated monoinfections, each specific type of co-infection, gender and growth status with diarrhoea and non-diarrhoea as binary outcomes (performed on Stata v11, StataCorp, College Station TX, USA). For the latter, a $p$-value of $<0.05$ was considered significant. The figure for mixed-infections (Fig. 2) was generated using the UpSetR package and restructured manually to generate the side by side bar graphs for comparing two groups [52]. 


\section{Supplementary information}

Supplementary information accompanies this paper at https://doi.org/10. 1186/s12866-020-01878-5.

Additional file 1: Table S1. List of gene accession numbers downloaded from GenBank (NCBI) (https://www.ncbi.nlm.nih.gov/ nucleotide/). Table S2. Demographic and clinical manifestations of DEC mono-infection in children hospitalized with diarrhoea.

\section{Abbreviations}

DEC: Diarrhoeagenic Escherichia coli; LMICs: Low-middle income countries; ETEC: Enterotoxigenic E. coli; EAEC: Enteroaggregative E. coli;

EPEC: Enteropathogenic E. coli; EIEC: Enteroinvasive E. coli; STEC: Shiga-toxin producing E. coli; HUS: Haemolytic uraemic syndrome; HCMC: Ho Chi Minh City; GEMS: Global Enteric Multicentre Study; CV\%: Co-efficient of variance; MC: MacConkey agar

\section{Acknowledgments}

We wish to acknowledge all members of the enteric infections group at Oxford University Clinical Research Unit (OUCRU) and the study teams at Hospital for Tropical Diseases (Infectious Paediatric Ward B), Children's Hospital 1 (Gastrointestinal Ward), Children's Hospital 2 (Gastrointestinal Ward), Hung Vuong Hospital and the Clinical Trial Unit and Data Management Centre (OUCRU). Importantly, we thank the enrolled children and their parents who consent to the study that made this study possible.

\section{Authors' contributions}

Conceptualization: SB. Formal analysis: VTD, LTPT. Provided samples: HLP, TTHC, NMN, LLV, CJ. Methodology: LTPT, HTT, LTQN, JIC, PVM, HLP, TTHC, NMN, LLV, CJ, IO, EH. Writing original draft: VTD, LTPT. Review and editing: SB, CJ, EH. Read and approved final version of manuscript: VTD, LTPT, HTT, LTQN, JIC, PVM, HLP, TTHC, NMN, LLV, CJ, IO, EH, SB

\section{Funding}

This work was supported by a Wellcome senior research fellowship to Stephen Baker to (215515/Z/19/Z). The funders had no role in the design and conduct of the study; collection, management, analysis, and interpretation of the data; preparation, review, or approval of the manuscript; and decision to submit the manuscript for publication.

\section{Availability of data and materials}

All data generated or analysed during this study are included in this published article and its supplementary information files.

\section{Ethics approval and consent to participate}

Ethical approval for this study was obtained from the OxTREC (OxTREC No. 1045-13 for cases and OxTREC No 1058-13 for controls) as well as from local partners, which included the Institutional Review Boards at Children's Hospital 1, Children's Hospital 2, The Hospital for Tropical Diseases, and Hung Vuong Hospital $(\mathrm{HVH})$. An informed consent form signed by a parent or guardian was required for enrolment.

\section{Consent for publication}

All authors have seen and approved the final version of this manuscript for publication.

\section{Competing interests}

Authors declare no competing interests.

\section{Author details}

${ }^{1}$ The Hospital for Tropical Diseases, Wellcome Trust Major Overseas Programme, Oxford University Clinical Research Unit, Ho Chi Minh City, Vietnam. ${ }^{2}$ Children's Hospital 1, Ho Chi Minh City, Vietnam. ${ }^{3}$ University of Medicine and Pharmacy at Ho Chi Minh City, Ho Chi Minh City, Vietnam. ${ }^{4}$ Children's Hospital 2, Ho Chi Minh City, Vietnam. ${ }^{5}$ The Hospital for Tropical Diseases, Ho Chi Minh City, Vietnam. ${ }^{6}$ National Infection Service, Public Health England, England, UK. ${ }^{7}$ Department of Pharmaceutical Microbiology, Faculty of Pharmacy, University of Ibadan, Ibadan, Nigeria. ${ }^{8}$ Cambridge Institute of Therapeutic Immunology \& Infectious Disease (CITIID)
Department of Medicine, Cambridge Biomedical Campus, University of Cambridge, Cambridge CB2 OAW, UK.

Received: 18 March 2020 Accepted: 25 June 2020

Published online: 03 July 2020

\section{References}

1. Liu L, Johnson HL, Cousens S, Perin J, Scott S, Lawn JE, et al. Global, regional, and national causes of child mortality: an updated systematic analysis for 2010 with time trends since 2000. Lancet. 2012;379:2151-61. https://doi.org/10.1016/S0140-6736(12)60560-1.

2. Walker CLF, Rudan I, Liu L, Nair H, Theodoratou E, Bhutta ZA, et al. Global burden of childhood pneumonia and diarrhoea. Lancet. 2013;381:1405-16. https://doi.org/10.1016/S0140-6736(13)60222-6.

3. Kirk MD, Pires SM, Black RE, Caipo M, Crump JA, Devleesschauwer B, et al. World Health Organization estimates of the global and regional disease burden of 22 foodborne bacterial, Protozoal, and viral diseases, 2010: a data synthesis. PLoS Med. 2015;12:1-21.

4. Scallan E, Mahon BE, Hoekstra RM, Griffin PM. Estimates of illnesses, hospitalizations, and deaths caused by major bacterial enteric pathogens in young children in the United States. Pediatr Infect Dis J. 2012;32:1. https:// doi.org/10.1097/INF.0b013e31827ca763.

5. Fletcher $S M, M c L a w s ~ M-L$, Ellis JT. Prevalence of gastrointestinal pathogens in developed and developing countries: systematic review and metaanalysis. J Public health Res. 2013;2:9. https://doi.org/10.4081/jphr.2013.e9.

6. Kotloff KL, Nataro JP, Blackwelder WC, Nasrin D, Farag TH, Panchalingam S, et al. Burden and aetiology of diarrhoeal disease in infants and young children in developing countries (the global enteric multicenter study, GEMS): a prospective, case-control study. Lancet. 2013;382:209-22.

7. Nataro JP, Kaper JB. Diarrheagenic Escherichia coli strains. Clin Microbiol Rev. 1998;11:142-201.

8. Yu J, Jing H, Lai S, Xu W, Li M, Wu J, et al. Etiology of diarrhea among children under the age five in China: results from a five-year surveillance. J Inf Secur. 2015. https://doi.org/10.1016/j.jinf.2015.03.001.

9. Trainor E, Iturriza-Gómara M, Ngwira B, Cunliffe N. Detection of enterotoxigenic $E$. coli in hospitalised children with and without diarrhoea in Blantyre, Malawi. Paediatr Int Child Health. 2016;36:102-5. https://doi.org/ 10.1179/2046905515Y.0000000014.

10. Begum Y A., Talukder K A., Azmi IJ, Shahnaij M, Sheikh A., Sharmin S, et al. Resistance pattern and molecular characterization of enterotoxigenic Escherichia coli (ETEC) strains isolated in Bangladesh. PLoS One. 2016;11:1-11.

11. Li Y, Luo Q, Shi X, Lin Y, Qiu Y, Lv D, et al. Phenotypic and genotypic characterization of clinical Enterotoxigenic Escherichia coli Isolates from Shenzhen, China. Foodborne Pathog Dis. 2017;14:333-40. https://doi.org/10. 1089/fpd.2016.2233.

12. Trabulsi L, Keller R, Tardelli GT. Typical and atypical enteropathogenic Escherichia coli. Emerg Infect Dis. 2002;8:508-13.

13. Croxen MA, Law RJ, Scholz R, Keeney KM, Wlodarska M, Finlay BB. Recent advances in understanding enteric pathogenic Escherichia coli. Clin Microbiol Rev. 2013;26:822-80.

14. CDC. Foodborne Diseases Active Surveillance Network (FoodNet ): FoodNet Surveillance Report for 2014 (Final Report). 2014;:1-25.

15. Gomes TAT, Elias WP, Scaletsky ICA, Guth BEC, Rodrigues JF, Piazza RMF, et al. Diarrheagenic Escherichia coli. Brazilian J Microbiol. 2016;47:3-30. https://doi.org/10.1016/j.bjm.2016.10.015.

16. Nguyen TV, Le Van P, Le Huy C, Gia KN, Weintraub A. Detection and characterization of diarrheagenic Escherichia coli from young children in Hanoi, Vietnam. J Clin Microbiol. 2005;43:755-60. https://doi.org/10.1128/ JCM.43.2.755-760.2005.

17. Thompson CN, Anders KL, Nhi LTQ, Tuyen HT, Van Minh P, Tu LTP, et al. A cohort study to define the age-specific incidence and risk factors of Shigella diarrhoeal infections in Vietnamese children: a study protocol. BMC Public Health. 2014;14:1289. https://doi.org/10.1186/1471-2458-14-1289.

18. lijima Y, Oundo JO, Hibino T, Saidi SM, Hinenoya A, Osawa K, et al. High prevalence of diarrheagenic Escherichia coli among children with diarrhea in Kenya. Jpn J Infect Dis. 2016. https://doi.org/10.7883/yoken.JJID.2016.064.

19. Ud-Din A, Wahid S. Relationship among Shigella spp. and enteroinvasive Escherichia coli (EIEC) and their differentiation. Braz J Microbiol. 2014;45: 1131-8. 
20. Ferdous M, Zhou K, Mellmann A, Morabito S, Croughs PD, De Boer RF, et al. Is Shiga toxin-negative Escherichia coli O157:H7 enteropathogenic or enterohemorrhagic Escherichia coli? Comprehensive molecular analysis using whole-genome sequencing. J Clin Microbiol. 2015;53:3530-8.

21. Ferdous M, Friedrich AW, Grundmann H, de Boer RF, Croughs PD, Islam MA, et al. Molecular characterization and phylogeny of Shiga toxin-producing Escherichia coli isolates obtained from two Dutch regions using whole genome sequencing. Clin Microbiol Infect. 2016;22, 642:e1-642.e9. https:// doi.org/10.1016/j.cmi.2016.03.028

22. Yan X, Fratamico PM, Bono JL, Baranzoni GM, Chen CY. Genome sequencing and comparative genomics provides insights on the evolutionary dynamics and pathogenic potential of different $\mathrm{H}$-serotypes of Shiga toxin-producing Escherichia coli O104. BMC Microbiol. 2015;15.

23. Rohde H, Qin J, Cui Y, Li D, Loman NJ, Hentschke M, et al. Open-source genomic analysis of Shiga-toxin-producing E. coli O104:H4. N Engl J Med. 2011;365:718-24. https://doi.org/10.1056/NEJMoa1 107643.

24. Liu J, Platts-Mills JA, Juma J, Kabir F, Nkeze J, Okoi C, et al. Use of quantitative molecular diagnostic methods to identify causes of diarrhoea in children: a reanalysis of the GEMS case-control study. Lancet. 2016;388: 1291-301. https://doi.org/10.1016/S0140-6736(16)31529-X.

25. Hien BTT, Scheutz F, Cam PD, Serichantalergs O, Huong TT, Thu TM, et al. Diarrheagenic Escherichia coli and Shigella strains isolated from children in a hospital case-control study in Hanoi, Vietnam. J Clin Microbiol. 2008;46:996-1004.

26. Tobias J, Kassem E, Rubinstein U, Bialik A, Vutukuru S-R, Navaro A, et al. Involvement of main diarrheagenic Escherichia coli, with emphasis on enteroaggregative $E$. coli, in severe non-epidemic pediatric diarrhea in a high-income country. BMC Infect Dis. 2015;15:1-7. https://doi.org/10.1186/ s12879-015-0804-4.

27. Bashir A, Ph D, Boisen N, Scheutz F, Paxinos EE, Sebra R, et al. Origins of the E.coli strain causing an outbreak of hemolytic uremic syndrome in Germany. N Engl J Med. 2011;365:1-9.

28. Čobeljić M, Miljković-Selimović B, Paunović-Todosijević D, Veličković Z, Lepšanović Z, Zec N, et al. Enteroaggregative Escherichia coli associated with an outbreak of diarrhoea in a neonatal nursery ward. Epidemiol Infect. 1996; 117:11-6.

29. Itoh Y, Nagano I, Kunishima M, Ezaki T. Laboratory investigation of Enteroaggregative Escherichia coli O Untypeable : H10 associated with a massive outbreak of gastrointestinal illness. J Clin Microbiol. 1997;35:2546-50.

30. Smith H, Cheasty T, Rowe B. Enteroaggregative Escherichia coli and outbreaks of gastroenteritis in UK. Lancet. 1997;350:814-5. https://doi.org/10. 1016/S0140-6736(05)62611-6.

31. Pai M, Kang G, Ramakrishna BS, Venkataraman A, Muliyil J. An epidemic of diarrhoea in south India caused by enteroaggregative Escherichia coli. Indian J Med Res. 1997;106 JULY:7-12.

32. Lima AAM, Soares AM, Filho JQS, Havt A, Lima IFN, Lima NL, et al. Enteroaggregative Escherichia coli subclinical infection and Coinfections and impaired child growth in the MAL-ED cohort study. J Pediatr Gastroenterol Nutr. 2018;66:325-33.

33. Langendorf C, Le Hello S, Moumouni A, Gouali M, Mamaty A-A, Grais RF, et al. Enteric bacterial pathogens in children with diarrhea in Niger: diversity and antimicrobial resistance. PLoS One. 2015;10:e0120275. https://doi.org/ 10.1371/journal.pone.0120275.

34. Araujo JM, Tabarelli GF, Aranda KRS, Fabbricotti SH, Fagundes-Neto U, Mendes CMF, et al. Typical enteroaggregative and atypical enteropathogenic types of Escherichia coli are the most prevalent diarrheaassociated pathotypes among Brazilian children. J Clin Microbiol. 2007;45: 3396-9.

35. Quiroga M, Oviedo P, Chinen I, Pegels E, Husulak E, Binztein N, et al. Asymptomatic infections by diarrheagenic Escherichia coli in children from Misiones, Argentina, during the first twenty months of their lives. Rev Inst Med Trop Sao Paulo. 2000;42:9-15.

36. Byrne L, Jenkins C, Launders N, Elson R, Adak GK. The epidemiology, microbiology and clinical impact of Shiga toxin-producing Escherichia coli in England, 2009-2012. Epidemiol Infect. 2015:1-13. https://doi.org/10.1017/ S0950268815000746.

37. Osawa K, Raharjo D, Wasito EB, Harijono S, Shigemura K, Osawa R, et al. Frequency of diarrheagenic Escherichia coli among children in Surabaya, Indonesia. Jpn J Infect Dis. 2013;66:446-8.

38. Valentini D, Vittucci AC, Grandin A, Tozzi AE, Russo C, Onori M, et al. Coinfection in acute gastroenteritis predicts a more severe clinical course in children. Eur J Clin Microbiol Infect Dis. 2013;32:909-15. https://doi.org/10. 1007/s10096-013-1825-9.

39. Ochoa TJ, Ecker L, Barletta F, Mispireta ML, Gil Al, Contreras C, et al. Agerelated susceptibility to infection with Diarrheagenic Escherichia coli among infants from Periurban areas in Lima, Peru. Clin Infect Dis. 2009;49:1694-702. https://doi.org/10.1086/648069.

40. Zhang S-X, Zhou Y-M, Xu W, Tian L-G, Chen J-X, Chen S-H, et al. Impact of co-infections with enteric pathogens on children suffering from acute diarrhea in Southwest China. Infect Dis poverty. 2016;5:64. https://doi.org/10. 1186/s40249-016-0157-2

41. Shrivastava AK, Kumar S, Mohakud NK, Suar M, Sahu PS. Multiple etiologies of infectious diarrhea and concurrent infections in a pediatric outpatientbased screening study in Odisha, India. Gut Pathog. 2017;9:16. https://doi. org/10.1186/s13099-017-0166-0.

42. World Health Organization. The Treatment of Diarrhoea. 2005. http://www. who.int/maternal_child_adolescent/documents/9241593180/en/.

43. Duong VT, Tuyen HT, Minh P, Van CJ, Le PH, TDH N, et al. No clinical benefit of empirical antimicrobial therapy for pediatric diarrhea in a high usage, high resistance setting. Clin Infect Dis. 2017; November:1-28. https:// doi.org/10.1093/cid/cix844.

44. Nataro JP, Yikang D, Yingkang D, Walker K. AggR, a transcriptional activator of aggregative adherence fimbria I expression in enteroaggregative Escherichia coli. J Bacteriol. 1994;176:4691-9. https://doi.org/10.1128/jb.176. 15.4691-4699.1994.

45. Hyland RM, Sun J, Griener TP, Mulvey GL, Klassen JS, Donnenberg MS, et al. The bundlin pilin protein of enteropathogenic Escherichia coli is an Nacetyllactosamine-specific lectin. Cell Microbiol. 2008;10:177-87. https://doi. org/10.1111/j.1462-5822.2007.01028.x

46. Chattaway MA, Jenkins C, Ciesielczuk H, Day M, Donascimento V, Day M, et al. Evidence of evolving extraintestinal enteroaggregative Escherichia coli ST38 clone. Emerg Infect Dis. 2014;20:1935-7.

47. Chattaway MA, Schaefer U, Tewolde R, Dallman TJ, Jenkins C. Identification of Escherichia coli and sequences. J Clin Microbiol. 2017;55:616-23.

48. Jenkins C, Lawson AJ, Cheasty T, Willshaw GA. Assessment of a real-time PCR for the detection and characterization of verocytotoxigenic Escherichia coli. J Med Microbiol. 2012;61:1082-5.

49. Frahm E, Obst U. Application of the fluorogenic probe technique (TaqMan P(R) to the detection of Enterococcus spp. and Escherichia coli in water samples. J Microbiol Methods. 2003;52:123-31.

50. de Onis M, Onyango AW, Borghi E, Garza C, Yang H. Comparison of the World Health Organization (WHO) child growth standards and the National Center for Health Statistics/WHO international growth reference: implications for child health programmes. Public Health Nutr. 2007;9:942-7. https://doi.org/10.1017/PHN20062005.

51. Fitch A, Fox C, Bauerly K, Gross A, Heim C, Judge-Dietz J, Kaufman T, Krych E, Kumar S, Landin D, Larson J, Leslie D, Martens N, Monaghan-Beery N, Newell T, O'Connor P, Spaniol A, Thomas A WB. Prevention and Management of Obesity for Children and Adolescents. Inst Clin Syst Improv. 2013;:10. https://www.icsi.org/_asset/tn5cd5/ObesityChildhood.pdf.

52. Conway JR, Lex A, Gehlenborg N. UpSetR: an R package for the visualization of intersecting sets and their properties. Bioinformatics. 2017;33:2938-40.

\section{Publisher's Note}

Springer Nature remains neutral with regard to jurisdictional claims in published maps and institutional affiliations.
Ready to submit your research? Choose BMC and benefit from:
- fast, convenient online submission
- thorough peer review by experienced researchers in your field
- rapid publication on acceptance
- support for research data, including large and complex data types
- gold Open Access which fosters wider collaboration and increased citations
- maximum visibility for your research: over $100 \mathrm{M}$ website views per year
At BMC, research is always in progress.
Learn more biomedcentral.com/submissions 